\title{
Por QUe ler os Clássicos? A IMPORTÂNCIA DA FILOSOFIA POLÍTICA PARA A COMPREENSÃO DA POLÍTICA CONTEMPORÂNEA
}

\author{
Rodrigo Gallo*
}

\begin{abstract}
RESUMO
O objetivo deste artigo é discutir a relevância da leitura dos autores clássicos da filosofia política para a compreensão do desenvolvimento do campo da Ciência Política no Ocidente. A hipótese levantada por este estudo é que autores como Maquiavel, Hobbes e Locke, dentre outros, não devem ser lidos exclusivamente dentro de seus contextos, pois, se interpretados a partir da longa duração, podemos perceber que esses filósofos são fundamentais para a fundação e para a consolidação de correntes políticas complexas, ainda que de um modo não sistematizado - e tal esforço intelectual deixa um legado para a política contemporânea e para áreas correlacionadas, como Políticas Públicas e Relações Internacionais.

Palavras-chave: pensamento político; filosofia política; clássicos do pensamento político; Ciência Política.
\end{abstract}

* Cientista político, especialista em Gestão Pública pela Universidade Federal de São Paulo (UNIFESP), mestre em História Social pela Universidade de São Paulo (USP), mestre e doutorando em Ciências Humanas e Sociais pela Universidade Federal do ABC (UFABC). É docente do curso de graduação de Relações Internacionais da Universidade São Judas Tadeu (USJT), do curso de Administração do Instituto Mauá de Tecnologia (IMT) e dos cursos de pós-graduação de Ciência Política e Relações Internacionais da Fundação Escola de Sociologia e Política de São Paulo (FESPSP).

Revista Páginas de Filosofia, v. 9, n. 2, p. 131-145, jul.-dez. 2020 


\title{
FALTA TÍTULO EM INGLÊS
}

\begin{abstract}
The objective of this article is to discuss the importance of reading the classic authors of political philosophy to understanding the development of the field of Political Science in the West World. The hypothesis of this paper is that the authors such as Machiavelli, Hobbes and Locke should not be read exclusively within their contexts, because, if interpreted from the long duration, we can see that these philosophers are fundamental for the foundation and for the consolidation of complex political currents, even in a non-systematic way - and such an intellectual effort leaves a legacy for contemporary politics, as Public Policies and International Relations.
\end{abstract}

Keywords: political thinking; political philosophy; classics of political thinking; Political Science.

\section{INTRODUÇÃo}

Ao refletir sobre o estatuto conferido às obras clássicas, o romancista italiano Italo Calvino sustentou a ideia de que as releituras desses textos consagrados devem ser vistas como esforços constantes de descobrimento, tal qual a primeira leitura - e que tendem a ser mais proveitosas com o passar do tempo, por conta do amadurecimento intelectual e do acúmulo de conhecimento (1993: 10-11). Isso ocorre porque esses livros, sejam eles relacionados à Filosofia, História ou Literatura, são profundamente complexos e paradigmáticos, e devem ser interpretados com cuidado, pois sempre podem acrescentar reflexões cada vez mais profundas, conforme o leitor aprofunda o conhecimento acerca desses filósofos. Logo, essa argumentação nos leva a pensar que os clássicos não se esgotam; cada nova leitura representa uma nova oportunidade de aprendizado.

Dentro desta perspectiva, as obras consagradas superam a principal dificuldade imposta a qualquer livro ou autor: a prova do tempo. Embora Tucídides, por exemplo, tenha escrito sobre a história da guerra entre atenienses e espartanos, um conflito relacionado ao mundo helênico do século $\mathrm{V}$ antes de Cristo, os argumentos do autor contribuem para refletirmos sobre política de poder e sobre rompimento de 
equilíbrio entre as cidades-Estado, algo fundamental para o campo de Relações Internacionais contemporâneas - prova de que tais filósofos inspiraram toda a geração de intelectuais do século XX (WOHLFORTH, 2008: 132). Do mesmo modo, John Locke não apenas teorizou sobre o princípio de direito à resistência no contexto do reinado de Jaime II, como também proporcionou às gerações futuras uma importante reflexão sobre o liberalismo político e a garantia das liberdades individuais no mundo moderno (KUNTZ, 2004: 119). Immanuel Kant, ao discorrer sobre o mundo cosmopolita e sua proposta para a paz perpétua, também lançaria bases elementares para pensarmos na construção das organizações internacionais no século XX (ANDRADE, 2005: 69).

Didaticamente falando, esses exemplos nos ajudam a compreender o quanto tais obras clássicas são lidas e reinterpretadas com o passar do tempo, oferecendo, desta forma, debates que não ficam circunscritos ao contexto dos autores em si, pois extrapolam sua própria realidade e possibilitam leituras bem mais abrangentes, de forma extemporânea. Diante desta característica, é possível afirmar que os clássicos têm uma relevância muito maior para o pensamento político. Dito de outra forma: o clássico, obviamente, ofereceu subsídios analíticos para explicar sua própria época; porém, esses autores também deixaram como legado um conjunto de conceitos que permitem a compreensão inclusive do mundo contemporâneo.

O objetivo deste artigo, portanto, é discutir a importância dos autores da filosofia política clássica para a compreensão e o desenvolvimento da política contemporânea, de modo a investigarmos o impacto dessas obras inclusive para as áreas correlatas à Ciência Política até agora. A hipótese deste estudo é que, lidos apenas como sujeitos presos a um contexto específico do tempo e do espaço, esses filósofos são fundamentais para o desenvolvimento do pensamento político, e nos legaram obras fundamentais; porém, se analisados a partir de um contexto mais amplo, pela perspectiva da longa duração, esses autores podem ser interpretados como marcos de fundação e consolidação de correntes políticas mais complexas, que influenciaram o desenvolvimento da política contemporânea, ainda que de um modo não-sistematizado. 
Dividimos este artigo em duas partes. Na primeira seção, discutimos a relevância dos clássicos para a construção de correntes teóricas complexas, cuja importância vai para além da própria obra de cada autor. Na segunda etapa deste estudo, refletimos sobre a herança da Filosofia Política para a consolidação de alguns campos das ciências humanas no século XX.

\section{A leitura dos Clássicos da filosofia política}

Afirmar que os autores clássicos superam a prova do tempo e do espaço, conforme fizemos na Introdução deste artigo, talvez não seja suficiente para convencer os leitores contemporâneos quanto à importância desses filósofos para o desenvolvimento da política contemporânea. Parte dessa descrença em relação aos clássicos pode ser atribuída ao processo de institucionalização das Ciências Sociais no século XX, que buscou incessantemente por métodos e técnicas de pesquisa inspiradas nas Ciências Naturais como forma de comprovar empiricamente os fenômenos analisados, inclusive no Brasil (BRANDÃO, 2004: 274-275). Deste modo, os estudos passaram a incorporar metodologias cada vez mais complexas, sempre orientadas pelo empirismo, normalmente com o suporte da estatística e técnicas qualitativas como entrevista - o que tornou a leitura dos clássicos da filosofia política uma tarefa considerada infrutífera por muitos pesquisadores atuais.

Com isso, muitos leitores podem ser levados a acreditar que se trata de leituras antigas e que não contribuem para os debates atuais sobre política, e que por isso não precisam ser estudados pelos analistas de política. Então, comecemos pela necessidade de desconstruir esse argumento.

De acordo com Vouga, a despeito da diferença de tempo, os clássicos nos permitem aprender com o passado e a superar o provincianismo de nossa época, pois exigem que pensemos a história não como a crônica de um período que já foi superado, mas sim como parte de um passado que influencia a realidade do nosso presente (VOUGA, 2004: 13-14). Isso significa dizer, por exemplo, que Maquiavel, ao analisar a fragmentação das cidades-estado italianas do século XVI por uma perspectiva realista - que vê o mundo como ele efetivamente é, e não 
como deveria ser -, também apresenta uma profunda discussão não-sistematizada sobre a distinção entre o idealismo e o realismo, fundamental para a passagem do pensamento político antigo para o pensamento político moderno (FORNAZIERI, 2006: 10) e que contribui para todo o debate sobre soberania e integridade territorial do século XX.

Sendo assim, autores clássicos emprestam seu olhar crítico para que nós, pesquisadores e leitores contemporâneos, possamos ver aquele passado a partir da perspectiva desses filósofos, valendo-nos de suas experiências, de suas reflexões e de suas interpretações para a realidade da época. Entretanto, por se tratarem de obras extremamente reflexivas, as discussões não se limitam a compreender a própria época em si, justamente porque há questões teóricas que ultrapassam as barreiras do tempo. Assim, parte da historiografia das ideias consideraria que o estudo da área também possibilita olharmos os clássicos tendo o nosso presente como grande indicador, buscando auxílio em suas teorias para explicar os problemas contemporâneos.

Essa tendência no campo da reflexão sobre a política também poderia ser expressa, ainda que de forma simplificada, nos seguintes termos: o que Aristóteles disse sobre a democracia que está sendo desvirtuado no mundo contemporâneo? O que Locke afirmou sobre a liberdade que se encontra empanado pelos poderes constituídos? Isso pode soar estranho, mas faz sentido quando se avalia que historiadores das ideias políticas, ou seja, mais propriamente, filósofos políticos, nos anos 1940/50, acreditavam no valor intemporal das ideias políticas, independentemente da época em que se vivia. (LOPES, 2011: 27-28)

Um dos principais focos de investigação dos clássicos seria o Estado, um elemento que praticamente todo filósofo da política moderna se propôs a investigar - cada um por sua perspectiva, construindo ou ajudando a consolidar uma corrente própria da filosofia política. Isso significa interpretar que os autores clássicos propuseram discussões que são praticamente atemporais e que servem para lançar luz sobre dilemas de praticamente qualquer época. É o valor extemporâneo das ideias políticas.

Nesse sentido, a história do pensamento político, ou o campo da história das ideias, não deveria ser considerado como a história dos 
filósofos, mas sim das filosofias: isso ocorre porque, embora não se possa tirar o indivíduo de seu contexto histórico-cultural, o trabalho de um pensador em si não está necessariamente circunscrito a pensarmos única e exclusivamente em sua obra, mas sim a um contexto mais amplo, que considere o modo como aquela filosofia foi criada, desenvolvida, ressignificada, até ter se transformado em algo maior do que se criador - resultado, consequentemente, no surgimento de complexas correntes de pensamento, que se expandiram e se consolidaram a partir da contribuição de sucessivas gerações de autores. Conforme sugere Skinner, do ponto de vista metodológico é importante reconhecermos que o pensamento desses autores está conectado a uma matriz social e intelectual, que permitiu o surgimento das suas obras (SKINNER, 1999: 10) - o que, por sua vez, demonstra o quanto o indivíduo está ligado a uma realidade, e o quanto esses filósofos estavam relacionados a contextos mais amplos.

Então, nesse aspecto, o mais importante é ler os autores clássicos e conseguir conectá-los aos sistemas filosóficos propostos por eles mesmo que propostos de forma indireta -, gerando debates fundamentais para a construção das correntes de pensamento. Isso permitiria alargar a visão sobre esses filósofos, que deixam um legado superior ao seu próprio nome. Desta forma, Maquiavel permite não apenas a compreensão sobre a condição histórico-política de Florença na Idade Moderna, mas também localizá-lo dentro de uma linha de pensamento realista, direta e indiretamente dando prosseguimento às discussões propostas muito anteriormente por Tucídides e sendo antecessor de Hobbes e Clausewitz, dentre tantos outros tributários da mesma doutrina; Kant, por sua vez, está associado ao mesmo processo liberal clássico de interpretar a sociedade, a exemplo do que já tinham feito Locke e Rousseau.

Conforme já indicamos, esse debate é complexo, e muitos leitores contemporâneos resistem à leitura dos clássicos, principalmente porque o campo de estudo da história do pensamento político é relativamente novo e data do início do século XX, e se desenvolveu de forma periférica dentro da academia - o que muitas vezes ainda contribui para que esses autores sejam relegados a um plano considerado me- 
nos importante para muitas pessoas. Naquele período inicial, houve a institucionalização da disciplina de história do pensamento político, ainda de forma marginal, com a proposta meramente de contextualizar autores do passado como uma espécie de catálogo cronológico, que trazia discussões sobre a doutrina de cada autor (LOPES, 2011: 19-20). Não havia, portanto, uma tentativa sistematizada de conectar os autores clássicos com um contexto mais amplo, que atravessasse o próprio período de vida daquele filósofo.

O desenvolvimento da disciplina, na década de 1930, quando estava em crescimento, ainda fazia com que diversas obras fossem lidas pela lógica da literatura política. Isso ocorria não necessariamente pelo conteúdo, mas sim pela estética utilizada por certos filósofos na redação dos textos. Talvez esse problema tenha afetado sobretudo alguns autores de caráter liberal, como Rousseau e Montesquieu, cuja forma de escrever lembrava de fato textos literários. Os autores realistas, Maquiavel e Hobbes, sofriam de outro mal: uma espécie de preconceito, ou mesmo de pós-conceito, relacionado à má interpretação das obras, que muitas vezes eram interpretadas pelo viés da moral religiosa como contraponto às suas constatações - o que certamente produzia leituras inadequadas.

Vouga destaca que os clássicos não nos dão algum tipo de dom para prever o futuro, mas, ao conhecermos suas ideias, conhecemos suas observações para o tempo futuro - que agora faz parte do nosso passado. E, assim, temos condições de verificar o quanto seus prognósticos foram ou não próximos daquilo que aconteceria.

(...) quando os clássicos do passado pensam o seu presente veem-no como uma série de possibilidades abrindo para muitos futuros possíveis. É justamente esse seu "não saber" que é para nós precioso, pois ele nos ajuda no nosso não saber. Não conhecemos nosso futuro, mas conhecemos o pensamento dos grandes homens quando o passado (que conhecemos) era futuro para eles, ou seja, sabemos o que pensavam quando não sabiam, e também sabemos a história transcorrida. E, assim como o florentino (Maquiavel), vamos ao passado procurando entender o tempo e a mudança, nossos mestres, para tentar de alguma forma agir sobre a realidade e ter ao menos a ilusão de domar o destino. (VOUGA, 2004: 15) 
Embora estejamos discutindo a relevância dos clássicos, é preciso admitirmos também que muitos autores da Antiguidade e da Idade Moderna não chegaram até os nossos dias, pois foram esquecidos com o passar do tempo. Não há uma resposta simples para esse questionamento. Talvez alguns não se mostraram capazes de servir como olhos para o passado e não puderam estabelecer conexões entre o que foi e o que é. Porém, a dinâmica da história social e da filosofia podem resgatar alguns desses autores, que eventualmente podem ser alçados a outra condição a partir do redescobrimento de suas obras e de novas interpretações contemporâneas para seus estudos.

0 mesmo pode ser dito acerca de autores orientais, cuja leitura é bastante incipiente no Ocidente - em especial no Brasil. A base do pensamento clássico a que temos acesso e que discutimos nas universidades brasileiras é majoritariamente composta por filósofos europeus. Logo, as tradições teóricas que debatemos têm, essencialmente, um viés conceitual ocidentalizado: deste modo, os conceitos de Estado, liberdade, poder, dentre outros, são lidos por nós a partir, sobretudo, da perspectiva eurocêntrica.

\section{O LEGAdo dOS ClÁsSicos PARA O SÉculo XX}

Até aqui, neste breve estudo, discutimos a relevância dos filósofos clássicos para a consolidação de linhas de pensamento mais amplas do que suas próprias obras, e constatamos que, de forma geral, esses autores estiveram relacionados à construção de correntes de pensamento mais complexas - ainda que não tenha sido essa a intenção desses pensadores. Agora, nesta segunda seção, precisamos discutir a herança que esses trabalhos deixaram para o século XX, influenciando não apenas a Ciência Política, mas também outras áreas próximas.

Diante disso, tomando como correta a hipótese deste artigo, de que a leitura dos autores dentro de um contexto maior permitiria compreendermos os clássicos como marcos de fundação e desenvolvimento de correntes de pensamento mais complexas, podemos basicamente agrupar esses filósofos e suas obras em pequenos grupos que ajudam a formar suas áreas dogmáticas - assim como mensurar sua importância 
para a Ciência Política contemporânea e, como já mencionamos, para os campos correlatos, em especial a área de Relações Internacionais - ramo das Ciências Sociais desenvolvido especialmente no século XX, a partir, principalmente, de perspectivas anglo-americanas, e que no Brasil está associado ao mesmo comitê da Coordenação de Aperfeiçoamento de Pessoal de Nível Superior (CAPES).

De um modo geral, podemos argumentar que Maquiavel, Hobbes e os pouco lembrados Tucídides e Clausewitz contribuíram para o desenvolvimento de uma corrente realista de pensamento, pautada pela presença do Estado como ator político central da sociedade (MAQUIAVEL, 2010), pela naturalização da guerra como sendo uma decorrência da natureza humana (CLAUSEWITZ, 1989), pela interpretação do mundo como um ambiente imperfeito e com certas características imutáveis, além da constante necessidade de sobrevivência (HOBBES, 2017). Essa perspectiva, que surge de forma não-sistematizada na Antiguidade, a partir da leitura tucidideana da Guerra do Peloponeso, passa pela Idade Moderna e chega ao mundo contemporâneo para oferecer subsídios teóricos para a compreensão do funcionamento do sistema internacional.

A leitura conjunta dos clássicos realistas, e não apenas de um autor, nos faria compreender que o realismo opera no campo do ser, e não do dever ser; o realismo atua por meio de uma lógica descritiva, ou seja, os autores analisam uma realidade, identificam um problema e discutem formas de sobreviver diante daquelas circunstâncias - sem cogitar a possibilidade de mudar o cenário para torná-lo ideal. 0 pragmatismo desses autores pode não ter inspirado completamente o desenvolvimento de um campo próprio e contemporâneo da Ciência Política, mas certamente serviu aos propósitos de estadistas e contribuiu para o advento de uma das escolas mais tradicionais das Relações Internacionais, permitindo que a lógica de defesa e segurança fosse adaptada para o jogo das grandes potências. 
Quadro 1: Os principais elementos da corrente realista

\begin{tabular}{|l|l|}
\hline Estado de natureza & $\begin{array}{l}\text { Homem é visto como um indivíduo cruel, vil e } \\
\text { egoísta. }\end{array}$ \\
\hline Natureza do Estado & $\begin{array}{l}\text { Principal ator da sociedade, que aplica a razão } \\
\text { e o pragmatismo para maximizar seus próprios } \\
\text { ganhos. }\end{array}$ \\
\hline Visão sobre a guerra & $\begin{array}{l}\text { Normalmente tratada como um evento normal } \\
\text { do sistema, causado pelo choque natural entre } \\
\text { os atores estatais. }\end{array}$ \\
\hline Visão sobre a paz & $\begin{array}{l}\text { A ordem é baseada em equilíbrio de poder, que } \\
\text { leva à interrupção dos conflitos. }\end{array}$ \\
\hline
\end{tabular}

Fonte: elaboração do autor

O Quadro 1 condensa alguns dos principais elementos da corrente teórica realista, que indicam que o modo como o Estado é conduzido reflete a própria natureza humana, tratada pelos filósofos como cruel, vil e egoísta. Essas bases conceituais certamente influenciariam os autores realistas do século XX, que herdaram a tradição desenvolvida entre a Antiguidade e a Modernidade e aplicaram, como já mencionamos, para novos campos de análise, como as Relações Internacionais. Especificamente neste caso, vemos a tradição do realismo constituir uma perspectiva de que a natureza humana, o pragmatismo e a busca pela satisfação dos interesses faz com que o sistema internacional seja considerado anárquico - o que maximiza os riscos de conflito no cenário internacional. Há, portanto, uma interpretação pessimista a partir da base teórica realista, estritamente inspirada na necessidade de conquistar e manter o poder (DONNELLY, 2005).

É importante, no entanto, relembrar que os autores realistas Maquiavel, Hobbes, Clausewitz, dentre outros - não se propuseram a criar um campo tão amplo: porém, a leitura das obras remete à continuidade das ideias, o que acabou consolidando a corrente de pensamento. Ainda assim, também é essencial refletirmos que não existe um único realismo político, uma vez que cada filósofo apresentou sua própria interpretação de mundo (BEITZ, 1999: 185). 
Por outro lado, Locke, Rousseau, os autores federalistas (Hamilton, Madison e Jay) e Kant contribuíram para a consolidação de uma corrente de pensamento considerada idealista por parte de alguns leitores, mas liberal para a maioria deles. Conjuntamente, podemos considerar se tratar de uma doutrina baseada na necessidade de o Estado garantir as liberdades individuais e coletivas, o que demanda a superação do Estado absolutismo ou de qualquer tipo de despotismo, para em seu lugar surgirem governos representativos, como a democracia ou a monarquia constitucional. 0 filosofia política liberal opera pela lógica do dever ser, e não do ser; o liberal atua tendo como base a perspectiva descritiva-prescritiva, uma vez que os autores analisam a realidade, identificam um problema, e a partir daí passam a elaborar formas de proporcionar uma mudança na realidade, superando os problemas existentes.

Sendo assim, o liberalismo se consolida a partir do momento em que cada filósofo procurou compreender os problemas de seu tempo, e propor modos de melhorar a realidade à sua volta - algo que deixaria como legado a necessidade de pensar nas possibilidades de transformação, sempre orientadas para a construção de um cenário ideal. 0 liberalismo, ao contrário do realismo, se transformou em uma ampla corrente de pensamento político contemporâneo, arregimentando inclusive uma militância que, consciente ou não de suas raízes históricas, propaga ideias liberais. Esses autores acabariam influenciando inclusive o modo como o jogo político é travado nas arenas atuais, exercendo influências também para o desenvolvimento de uma grande corrente teórica para as Relações Internacionais, tão clássica quanto o realismo, e muitas vezes deixando um legado para o processo pelo qual pensamos certas lógicas da Gestão Pública. 
Quadro 2: Os principais elementos da corrente liberal

\begin{tabular}{|l|l|}
\hline Estado de natureza & $\begin{array}{l}\text { Parte dos autores vê o homem como um indiví- } \\
\text { duo bom, inclinado para fazer o bem, enquanto } \\
\text { outros o tratam como uma criatura neutra. }\end{array}$ \\
\hline Natureza do Estado & $\begin{array}{l}\text { Divide o protagonismo com outros atores, muitos } \\
\text { deles não-estatais. }\end{array}$ \\
\hline Visão sobre a guerra & $\begin{array}{l}\text { Uma anomalia que deve ser superada, pois repre- } \\
\text { senta o impulso, e não a razão. }\end{array}$ \\
\hline Visão sobre a paz & $\begin{array}{l}\text { Deve ser alcançada a partir da cooperação entre } \\
\text { os Estados, que racionalmente são orientados } \\
\text { para a paz. }\end{array}$ \\
\hline
\end{tabular}

Fonte: elaboração do autor

O Quadro 2 indica que a tradição criada pelos autores liberais, como Locke, Rousseau e Kant, deixou como legado a percepção de que o Estado é um ator orientado pela busca racional da paz. Nesse aspecto, o ser humano é retratado como um indivíduo racional, cuja natureza normalmente oscila entre positiva (ROUSSEAU, 2016) e neutra (LOCKE, 2014), e que aplica a racionalidade para a produção do melhor governo possível - inclusive como forma de corrigir as anomalias e buscar garantias jurídicas para que haja o respeito às instituições e às liberdades - o que também pode resultar na busca de uma paz estável e duradoura a partir da articulação de princípios republicanos (KANT, 2008).

A exemplo do corpus realista, o liberalismo também não corresponde a um grupo homogêneo de autores e conceitos, pois cada autor nos oferece sua própria percepção de mundo. Ainda assim, é perceptível que esses filósofos, cada um à sua maneira, deixou como legado um amplo debate acerca do mundo ideal - que influencia até a contemporaneidade um grande conjunto de militantes, gestores públicos e estadistas. 0 fato é que tais considerações, oriundas de séculos de reflexões, ainda exercem forte influência sobre o processo político.

De forma didática, procuramos demonstrar não apenas a importância das obras clássicas do Ocidente em si, mas principalmente a contribuição dessas filosofias na longa duração, ou seja, o quanto 
esses livros foram fundamentais para construir interpretações de realidade que são válidas até hoje como instrumento de análise para os pesquisadores contemporâneos.

E para além dos usos contemporâneos da filosofia política aplicada a áreas correlatas da Ciência Política, acreditamos que um argumento de Miller ilustra bem a relevância da filosofia política para os tempos atuais:

Podemos definir a filosofia política como uma investigação sobre a natureza, as causas e os efeitos do bom e do mau governo, num quadro não apenas restrito a esse propósito, mas expressa de forma impressionante três ideias que estão no cerne do assunto. A primeira é que o bom e o mau governo afetam profundamente a qualidade de vida das pessoas. (...) A segunda ideia é que a forma de nosso governo não é pré-determinada: nós temos uma escolha a fazer. A terceira ideia é que podemos saber o que distingue os bons governos dos maus: nós podemos traçar os efeitos de diferentes formas de governo e podemos aprender que qualidades vão erigir a melhor forma de governo. (MILLER, 2003: 2-3)

Com esse argumento, podemos afirmar que os sistemas filosóficos desenvolvidos durante séculos pelos autores clássicos nos proporcionam, também, um conjunto de reflexões acerca do modo como somos governados até os dias atuais, e como compreender os efeitos de cada decisão política. É, mais uma vez, uma demonstração da atemporalidade das obras clássicas e das correntes de pensamento edificadas a partir delas, e que são sim leituras e discussões intelectuais fundamentais para nós, indivíduos do Mundo Contemporâneo.

\section{CONSIDERAÇões FINAIS}

Com base nesse breve estudo, cujo objetivo é debater a relevância da filosofia política clássica, entendemos que nossa hipótese está comprovada: a leitura isolada de um autor clássico serve, obviamente, para compreender a obra de um filósofo que foi singular para o desenvolvimento do pensamento político Ocidental. No entanto, a leitura dessa obra num contexto mais amplo, que explore a filosofia mais do que o filósofo, permite compreender como a obra está situada dentro 
de um sistema, e como aquele sistema se apresenta como um marco importante para toda uma corrente de pensamento.

Neste aspecto, é notório que as obras de autores como Maquiavel, Locke, Kant e tantos outros ainda influencia o processo decisório, nos ajuda a compreender a forma como somos governados e, cientificamente falando, estão relacionadas ao desenvolvimento e à consolidação de campos contemporâneos, especialmente as Relações Internacionais e as Políticas Públicas.

Desta forma, ler um autor clássico é não apenas conhecer a interpretação do filósofo acerca dos problemas do seu tempo, mas também redescobrir constantemente formas de interpretar problemas contemporâneos.

\section{REFERÊNCIAS}

ANDRADE, Regis de Castro. Kant: a liberdade, o indivíduo e a república. In. WEFFORT, Francisco (org.). Os clássicos da política - vol. 2. São Paulo: Ática, 2005, p. 47-100.

BEITZ, Charles. Political theory and International Relations. Princeton: Princeton University Press, 1999.

BRANDÃO, Gilson Marçal. Teoria política e institucionalização acadêmica. In: QUIRINO, Célia Galvão; VOUGA, Cláudio; BRANDÃO, Gildo (org.). Clássicos do pensamento político. São Paulo: Editora USP, 2004, p. 271-277.

CALVINO, Italo. Por que ler os clássicos. São Paulo: Cia. das Letras, 1993.

CLAUSEWITZ, Carl von. On War. Princeton: Princeton University Press, 1989.

DONNELLY, Jack. Realism. In: BURCHILL, Scott; LINKLATER, Andrew; DEVETAK, Richard (org). Theories of International Relations. New York: Palgrave Macmillan, 2005, p. 29-54.

FORNAZIERI, Aldo. Maquiavel e o bom governo. Tese (doutorado em Ciência Política). Faculdade de Filosofia, Letras e Ciências Humanas, Universidade de São Paulo. São Paulo, 2006.

HOBBES, Thomas. Leviathan. London: Penguin, 2017.

KANT, Immanuel. A Paz perpétua. Porto Alegre: L\&PM, 2008.

KUNTZ, Rolf. Locke: liberdade, igualdade e propriedade. In: QUIRINO, Célia Galvão; VOUGA, Cláudio; BRANDÃO, Gildo (org.). Clássicos do pensamento político. São Paulo: Editora USP, 2004, p. 91-120. 
LOCKE. John. Segundo tratado sobre o governo civil. São Paulo: EdiPro, 2014.

LOPES, Marcos Antônio. Para ler os clássicos do pensamento político. Rio de Janeiro: Editora FGV, 2011.

MAQUIAVEL, Nicolau. O Príncipe. São Paulo: Penguin, 2010.

MILLER, David. Political philosophy: a very short introduction. Oxford: Oxford University Press, 2003.

ROUSSEAU, Jean-Jacques. The social contract. London: Penguin, 2016.

SKINNER, Quentin. As fundações do pensamento político moderno. São Paulo: Companhia das Letras, 1999.

VOUGA, Claudio. A leitura dos clássicos. In: QUIRINO, Célia Galvão; VOUGA, Cláudio; BRANDÃO, Gildo (org.). Clássicos do pensamento político. São Paulo: Editora USP, 2004, p. 13-22.

WOHLFORTH, William. Realism. In: REUS-SMIT, Christian; SNIDAL, Duncan (ed.). Oxford: Oxford University Press, 2008. p. 131-149.

Revista Páginas de Filosofia, v. 9, n. 2, p. 131-145, jul.-dez. 2020 